\title{
Tingkat pengetahuan remaja putri terhadap menstrual hygiene pada siswi SMP N 2 Jantho Aceh Besar
}

\author{
Lia Lajuna ${ }^{1}$, Nurlaili Ramli ${ }^{2}$, Nora Liana ${ }^{3}$ \\ 1,2,3 Jurusan Kebidanan, Politeknik Kesehatan Kemenkes Aceh. Email: lialajuna988@gmail.com
}

\begin{abstract}
Menstrual hygiene and knowledge among adolescent school girls of Jantho, Aceh Besar-Indonesia
\end{abstract}

Background: The age of teenager is the transition period from childhood to adulthood which is characterized by physical, psychological and psycho social changes. One of the biggest changes in adolescents is menstruation. Teens who experience menstruation need to maintain reproductive health. They need special knowledge about menstruation to avoid health problems.

Purpose: This study was to analyze the relationship between menstrual hygiene and knowledge among adolescent school girls of Jantho, Aceh Besar-Indonesia

Methods: Type of quantitative research, analytical design using across-sectional approach. the number of samples is 30 people, by purposive random sampling. Data analysis using kendall's Tau.

Results: The results showed that the relationship between menstrual hygiene and knowledge among adolescent school girls of jantho, aceh besar-indonesia, indicated by the value of $p$ value of 0.015 and the value of $\mathrm{T}$ obtained by 0.532 . Menstrual hygiene is poor because menstrual hygiene and practice during menstruation was inappropriate due to lack of knowledge, and need more health education in reproductive health and inadequate support for school facilities

Conclusion: The level of knowledge among adolescent school girls of Jantho, Aceh Besar-Indonesia was in poor category. There is a relationship between menstrual hygiene and knowledge among adolescent school girls of Jantho, Aceh Besar-Indonesia

\section{Keywords: Menstrual hygiene; Knowledge; Adolescent school girls}

Pendahuluan: Remaja merupakan periode transisi dari masa anak ke masa dewasa yang ditandai dengan adanya perubahan fisik, psikis dan psikososial. Salah satu perubahan terbesar pada remaja terjadi mentruasi dan rentan terhadap masalah kesehatan. Remaja yang mengalami menstruasi, perlu menjaga pemeliharaan kesehatan reproduksi. Remaja perlu pengetahuan mentruasi agar terhindar dari masalah kesehatan.

Tujuan: Mengetahui dan menganalisis hubungan tingkat pengetahuan remaja putri terhadap menstrual hygiene

Metode: Jenis penelitian kuantitatif, rancangan analitik menggunakan pendekatan cross-sectional. Jumlah sampel sebanyak 30,dipilih secara purpuse sampling. Analisa data menggunakan uji statistik kendall tau.

Hasil: Hasil penelitian menunjukan terdapat hubungan antara tingkat pengetahuan remaja putri tentang menstruasi dengan menstrual hygiene saat menstruasi, ditunjukkan dengan nilai $p$ value sebesar 0,015 dan nilai T didapatkan 0,532. Menstrual hygiene masih buruk dikarenakan perilaku menstrual hygiene saat menstruasi masih salah. Penyebab lainya karena kurangnya pengetahuan, belum mendapatkan penyuluhan kesehatan reproduksi dan dukungan fasilitas sekolah yang belum memadai.

Simpulan: Tingkat pengetahuan wanita muda tentang menstruasi di SMP 2 Kota Jantho termasuk dalam kategori kurang. Ada hubungan antara tingkat pengetahuan remaja putri tentang menstruasi dengan menstrual hygiene saat menstruasi

\section{Kata kunci : Pengetahuan; Remaja Putri; Menstrual hygiene}

\section{PENDAHULUAN}

Remaja merupakan masa transisi dari anakanak menuju dewasa. Masa remaja terjadi saat usia usia 10-18 tahun (Kementrian kesehatan, 2014). Remaja yang berusia 15-19 tahun di Indonesia berjumlah 20890734 jiwa (Badan Pusat 
Tingkat pengetahuan remaja putri terhadap menstrual hygiene pada siswi SMP N 2 Jantho Aceh Besar

Statistik, 2013). Masa remaja merupakan periode transisi dari masa anak ke masa dewasa yang ditandai dengan adanya perubahan fisik, emosi dan psikis. Masa remaja merupakan periode pematangan organ reproduksi manusia yakni mulai usia 10-19 tahun (Benita, Dewantiningrum, \& Maharani, 2012).

Pada Masa remaja terjadi periode masa pematangan organ reproduksi manusia yang sdisebut masa pubertas (Kementrian kesehatan, 2014). Masa pematangan organ reproduksi ditandai dengan adanya menstruasi pertama pada anak perempuan yang disebut menarche. Menarche merupakan menstruasi pertama perempuan dimana cairan darah keluar dari alat kelamin wanita yang berasal dari luruhnya lapisan dinding dalam rahim (Asna, 2011).

Pada umumnya siklus menstruasi yang normal terjadi setiap 21-35 hari sekali dengan rata-rata 28 hari (Greydanus, Sorrel, Omar \& Dodich, 2012). Saat menstruasi Remaja putri perlu melakukan menstrual hygiene agar merasa nyaman dalam beraktivitas, percaya diri, dan tidak dijauhi teman karena bau amis (Yusiana \& Saputri, 2016).

Menstrual hygiene pada saat menstruasi merupakan komponen hygiene perorangan yang memegang peranan penting dalam status perilaku kesehatan seseorang, termasuk menghindari adanya gangguan pada fungsi alat reproduksi (Purti \& Setiyanimgsih). Menstrual hygiene saat menstruasi dipengaruhi oleh tingkat pengetahuan tentang kesehatan reproduksi. Rendahnya pengetahuan tentang kesehatan reproduksi memungkinkan perempuan tidak melakukan menstrual hygiene yang benar pada saat menstruasi yang dapat membahayakan kesehatan reproduksinya sendiri (Dewi, 2013). menunjukkan bahwa perilaku higiene organ reproduksi yang kurang merupakan salah satu faktor risiko terjadinya kanker serviks pada wanita di Kota Denpasar.

Pengetahuan tentang kesehatan reproduksi dan perilaku hidup bersih dan sehat (PHBS) juga sangat penting diperhatikan. Oleh karena itu remaja putri perlu diberikan informasi, sosialisasi dan pengetahuan umum mengenai kesehatan reproduksi. Persepsi yang tidak tepat tentang perawatan organ reproduksi dapat mengakibatkan perawatan organ reproduksi dilakukan kurang maksimal (Purwaningrum, 2017).

Hasil observasi awal ditemukan bahwa siswi SMPN 2 Kota Jantho Aceh Besar mayoritas siswi belum mengetahui mengenai kesehatan reproduksi. Selain itu juga, belum pernah petugas kesehatan datang ke sekolah memberikan sosialisasi tentang kesehatan reproduksi, tidak tersedianya informasi kesehatan dan sedikitnya pelajaran yang membahas tentang menstruasi..

\section{METODE PENELITIAN}

Penelitian ini menggunakan metode kuantitatif korelasional dengan pendekatan crosssectional. Penelitian ini dilakukan di SMPN 2 Kota Jantho Aceh Besar dari tanggal 1 sampai 20 November 2018. Populasi dalam penelitian ini adalah semua remaja putri yang telah menstruasi di SMPN 2 Kota Jantho. Sampel diambil sebanyak 30 orang siswa. Data primer di dapat langsung dari kuesioner dan wawancara. Data sekunder diperoleh dari studi pustaka dan informasi pendukung lainya. Analisis data menggunakan pendekatan statistik Kendall Tau untuk analisa bivariat.

Lia Lajuna', Nurlaili Ramli ${ }^{2}$, Nora Liana ${ }^{3}$ Jurusan Kebidanan, Politeknik Kesehatan Kemenkes Aceh. Email: lialajuna988@gmail.com 
HASIL

Tabel 1. Karakteristik Responden berdasarkan usia dan kelas $\mathrm{N}=30$

\begin{tabular}{ccc}
\hline Usia & Frekuensi (f) & Persentase (\%) \\
\hline 12 Tahun & 1 & 3 \\
13 Tahun & 4 & 14 \\
14 Tahun & 6 & 20 \\
15 Tahun & 12 & 40 \\
16 Tahun & 7 & 23 \\
Kelas & & \\
VII & 2 & 7 \\
VIII & 10 & 33 \\
IX & 18 & 60 \\
Total & 30 & $100 \%$ \\
\hline
\end{tabular}

Tabel 1. menunjukan usia responden rata-rata usia remaja putri dalam penelitian ini adalah 15 tahun, dengan usia termuda 12 tahun dan tertua 16 tahun. Responden terbanyak ada pada kelas IX yaitu 18 orang (60\%), dan paling sedikit pada kelas VII hanya 2 orang(7\%)

Tabel 2. Distribusi Frekuensi Tingkat Pengetahuan Remaja Putri Tentang Menstruasi N=30

\begin{tabular}{lcc}
\hline Tingkat Pengetahuan & Frekuensi (f) & Persentase (\%) \\
\hline Baik & 0 & 0 \\
Cukup & 6 & 20 \\
Kurang & 24 & 80 \\
& & \\
Menstrual Hygiene & 8 & 27 \\
Baik & 22 & 73 \\
Buruk & 0 & 0 \\
Sangat buruk & 30 & $100 \%$ \\
Total & & \\
\hline
\end{tabular}

Berdasarkan tabel 2, diketahui bahwa responden yang memiliki tingkat pengetahuan cukup sebanyak 6 orang (20\%) dan yang memiliki tingkat pengetahuan kurang sebanyak 24 orang $(80 \%)$. Kemudian responden yang memiliki menstrual hygiene yang baik sebanyak 8 orang (27\%) dan yang memiliki menstrual hygiene buruk sebanyak 22 orang $(73 \%)$.

Lia Lajuna', Nurlaili Ramli ${ }^{2}$, Nora Liana ${ }^{3}$ Jurusan Kebidanan, Politeknik Kesehatan Kemenkes Aceh. Email: lialajuna988@gmail.com 
Tingkat pengetahuan remaja putri terhadap menstrual hygiene pada siswi SMP N 2 Jantho Aceh Besar

Tabel 3. Hubungan Tingkat Pengetahuan Remaja Putri Tentang Menstruasi dengan Menstrual Hygiene

\begin{tabular}{lccccccccc}
\hline \multirow{2}{*}{ Pengetahuan } & \multicolumn{3}{l}{ Menstrual Hygiene } & \multicolumn{3}{c}{ Jumlah } & & T & p value \\
\cline { 2 - 7 } & \multicolumn{2}{c}{ Baik } & \multicolumn{3}{c}{ Buruk } & & & \\
\cline { 2 - 8 } & $\mathrm{f}$ & $\%$ & $\mathrm{f}$ & $\%$ & $\mathrm{f}$ & $\%$ & & \\
\hline Cukup & 4 & 66,7 & 2 & 33,3 & 6 & 100 & 0,452 & 0,015 \\
Kurang & 4 & 16,7 & 20 & 83,3 & 24 & 100 & & \\
\hline
\end{tabular}

Berdasarkan tabel 3 , diatas responden yang memiliki tingkat pengetahuan katagori cukup, terdapat 4 responden $(66,7 \%)$ yang memiliki menstrual hygiene baik dan 2 responden $(33,3 \%)$ yang memiliki menstrual hygiene buruk. Sedangkan dari 24 responden dengan tingkat pengetahuan katagori kurang, terdapat 4 responden $(16,7 \%)$ yang memiliki menstrual hygiene baik dan 20 responden $(83,3 \%)$ yang memiliki menstrual hygiene masih buruk. Hasil uji statistik Kendall Tau menunjukkan bahwa semakin baik tingkat pengetahuan remaja tentang menstruasi semakin baik menstrual hygienenya saat menstruasi $(p$-value $=0,015)$. Nilai $T$ didapatkan 0,452 mengandung arti tingkat kekuatan hubungan kedua variabel bersifat sedang, hal tersebut dikarena terletak dalam rentang 0,40-0,599 dan mempunyai arah korelasi yang bersifat positif.

\section{PEMBAHASAN}

Hasil penelitian menunjukkan bahwa sebagian besar responden kurang memiliki pengetahuan tentang menstruasi. Kurangnya informasi dan materi tentang menstruasi pada mata pelajaran IPA menjadi salah salah satu penyebabnya (Chaniarosi, 2014). Artinya semakin sedikit informasi yang diterima tentang menstruasi semakin rendah pula tingkat pengetahuan responden tentang menstruasi. Sedangkan Responden yang memiliki pengetahuan cukup mengakui pernah mendapatkan informasi dari orang tua dan pernah membaca buku. Seseorang yang memiliki sumber informasi cendrung memiliki pengetahuan yang lebih luas. Semakin banyak informasi yang masuk semakin banyak pula pengetahuan yang didapat tentang kesehatan.

Penelitian yang menunjukkan bahwa semua siswi mendapatkan informasi tentang perawatan diri saat menstruasi dari berbagai macam sumber informasi dan sumber informasi terbanyak adalah ibu mereka. Ibu merupakan orang yang paling dekat dengan remaja perempuan dan menyampaikan informasi tentang perawatan diri saat kepada puteri mereka. Selain ibu, Guru juga berperan penting dalam memberikan informasi dan meningkatkan perilaku siswi mengenai menstruasi dan perawatan dirinya kepada anak didiknya sehingga mendapatkan informasi yang benar tentang prilaku menstrual higine saat menstruasi (Solehati, Ermiati, Trisyani, \& Hermayanti, 2017).

Hasil penelitian menunjukkan bahwa ada hubungan antara tingkat pengetahuan remaja putri tentang menstruasi dengan menstrual hygiene saat menstruasi dengan nilai pvalue $=0,015$, nilai tersebut artinya ada hubungan signifikan. Sedangkan Nilai T didapatkan 0,452 , mengandung arti yang tingkat kekuatan hubungan kedua variabel tersebut bersifat sedang karena terletak dalam rentang 0,40-0,599.

Penelitian yang menunjukkan bahwa terdapat pengaruh pendidikan kesehatan terhadap kemampuan remaja putri dalam perawatan organ reproduksi. Hasil penelitian juga menunjukkan bahwa terdapat peningkatan kemampuan remaja putri dalam melakukan perawatan organ reproduksi sesudah diberikan pendidikan kesehatan $(p$-value $=0,001)$ (Sumiarsih, Winarsi, Wahidun, 2019).

Faktor yang mempengaruhi menstrual hygiene saat menstruasi berhubungan erat dengan teman sebaya, ketersediaan fasilitas alat pembersih, sikap dan pengetahuan (Suryati, 2012). Ibu merupakan sumber informasi yang paling utama tentang kebersihan saat menstruasi, diikuti oleh kakak, teman-teman dan guru (Thakre, Thakre,

Lia Lajuna', Nurlaili Ramli ${ }^{2}$, Nora Liana ${ }^{3}$ Jurusan Kebidanan, Politeknik Kesehatan Kemenkes Aceh. Email: lialajuna988@gmail.com 
Tingkat pengetahuan remaja putri terhadap menstrual hygiene pada siswi SMP N 2 Jantho Aceh Besar

Reddy, Rathi, Pathak, \& Ughade, 2011). Pengetahuan mentruasi perlu diberikan kepada remaja, agar memiliki pengetahuan dan informasi yang benar, sehingga diharapkan dapat memiliki sikap dan perilaku yang bertanggung jawab terhadap proses mentruasi.

Remaja putri yang memiliki menstrual hygiene masih buruk dikarenakan perilaku menstrual hygiene saat menstruasi yang masih salah (Yusiana \& Saputri, 2016). Hal tersebut disebabkan kurangnya pengetahuan yang mereka miliki tentang menstrual hygiene yang benar saat menstruasi. Selain itu juga dikarenakan mereka belum pernah mendapatkan penyuluhan tentang kesehatan reproduksi dan di dukung oleh fasilitas sekolah yang kurang memadai (Sugiatno \& Sujaryo, 2011).

Kewajiban menjaga kebersihan saat menstruasi sering diabaikan oleh remaja. Faktor penyebabnya antara lain karena ketidaktahuan atau karena kurangnya perhatian dalam mengikuti anjuran yang diberikan (Hidayah, 2017). Selain itu, dukungan fasilitas yang memadai sangat penting untuk diperhatikan terutama ditempat-tempat umum seperti sekolah, mesjid, tempat wisata, rumah sakit, stasiun pasar dan lainnya (Sinaga, Saribanon, Sa'adah, Salamah, Murty, Trisnamiati \& Lorita, 2017). Menstrual Hygiene saat menstruasi sangat penting diinformasikan pada remaja untuk mencegah terjadinya infeksi pada saluran reproduksi. Remaja perlu diberikan informasi tentang pentingnya menstrual hygiene saat menstruasi yang dapat dimasukkan dalam kurikulum sekolah melalui materi tentang kesehatan reproduksi wanita, informasi dari media dibutuhkan dan orangtua yang membahas tentang menstruasi dengan rinci sehingga remaja tidak merasa tabu untuk berdiskusi dengan orangtua terutama pada ibunya (Nurilita, 2014).

\section{SIMPULAN}

Tingkat pengetahuan remaja putri tentang menstruasi pada SMPN 2 Kota Jantho termasuk dalam kategori kurang. Menstrual Hygiene saat menstruasi pada siswi termasuk dalam kategori buruk. Terdapat hubungan antara tingkat pengetahuan remaja putri tentang menstruasi dengan menstrual hygiene saat menstruasi yang ditunjukkan dengan $p$ value sebesar 0,015 dan nilai $\mathrm{T}$ didapatkan 0,452 dengan arah korelasi positif. Kolerasi positif menunjukan asumsi semakin baik tingkat pengetahuannya tentang menstruasi semakin baik menstrual hygiene saat menstruasi.

\section{SARAN}

Diharapkan informasi tentang menstrual hygiene pada remaja dilakukan melalui penambahan pembelajaran disekolah, melalui media dan orangtua terutama ibu agar lebih terbuka pada anaknya dalam memberikan informasi tentang menstruasi sehingga remaja putri dapat berprilaku baik dalam menstrual hygienenya saat menstruasi

\section{DAFTAR PUSTAKA}

Asna, K. (2011). Hubungan antara pengetahuan dan sikap terhadap kesehatan reproduksi dengan perilaku seksual pra nikah pada siswa di Sma Negeri 14 Kota Semarang Tahun Ajaran 2010/2011 (Doctoral dissertation, Universitas Negeri Semarang).

Badan Penelitian dan Pengembangan Kesehatan Kementerian Kesehatan Republik Indonesia. (2013). Penyajian pokok-pokok hasil riset kesehatan dasar 2013. Jakarta. Kemenkes RI

Badan Pusat Statistik. (2012). Perkembangan beberapa indikator utama sosial-ekonomi Indonesia. Jakarta. Katalog BPS/BPS Catalogue, 3101015.

Benita, N. R., Dewantiningrum, J., \& Maharani, N. (2012). Pengaruh penyuluhan terhadap tingkat pengetahuan kesehatan reproduksi pada remaja siswa SMP Kristen Gergaji (Doctoral dissertation, Fakultas Kedokteran).

Chaniarosi, L. F. (2014). Identifikasi miskonsepsi guru Biologi SMA Kelas XI IPA pada konsep sistem reproduksi manusia. Jurnal edubio Tropika, 2(2).

Lia Lajuna', Nurlaili Ramli ${ }^{2}$, Nora Liana ${ }^{3}$ Jurusan Kebidanan, Politeknik Kesehatan Kemenkes Aceh. Email: lialajuna988@gmail.com 
Tingkat pengetahuan remaja putri terhadap menstrual hygiene pada siswi SMP N 2 Jantho Aceh Besar

Dewi, I. G. A. A. N. (2013). Paparan asap rokok dan higiene diri merupakan faktor risiko lesi prakanker leher rahim di Kota Denpasar tahun 2012. Public Health and Preventive Medicine Archive, 1(1).

Greydanus, D. E., Sorrel, S., Omar, H. A., \& Dodich, C. B. (2012). Adolescent female menstrual disorders. International Journal of Child and Adolescent Health, 5(4), 357.

Hidayah, A. S. (2017). Konsep Islam tentang pendidikan seks bagi anak dalam keluarga: dalam buku At Tarbiyah al Jinsiyah lil Athfāl wa al Bālighīn karya Yusuf Madani (Doctoral dissertation, UIN Walisongo).

Nurlita, W. (2014). Gambaran tingkat pengetahuan dan perilaku menjaga kebersihan organ genetalia eksterna pada siswi MI Pembangunan.

Purwaningrum, A. E. (2017). Gambaran perilaku menstrual hygiene remaja putri kelas VIII dan IX Saat Menstruasi Di Smp N 1 Gamping Kabupaten Sleman.

Putri, N. A., \& Setianingsih, A. (2016). Hubungan Pengetahuan dan Sikap Terhadap Perilaku Menstrual Hygiene Mentruasi. Jurnal IImu Kesehatan Masyarakat, 5(1), 15-23.

Sinaga, E., Saribanon, N., Sa'adah, N., Salamah, U., Murti, Y. A., Trisnamiati, A., \& Lorita, S. (2017). Manajemen Kesehatan Menstruasi. Universitas Nasional.
Solehati, T., Ermiati, E., Trisyani, M., \& Hermayanti, Y. (2017). Hubungan sumber informasi dan Usia Remaja Puteri dengan Perilaku Perawatan Diri saat Menstruasi. Jurnal Keperawatan Padjadjaran, 5(2).

Sugiyanto, Z., \& Suharyo, S. (2011). Analisis praktik pendidikan kesehatan reproduksi remaja oleh guru bimbingan dan konseling pada SMP yang berbasis agama di Kota Semarang. Jurnal Dian, 11(1).

Surmiasih, S., Winarsi, N., \& Wahidun, W. (2019). Pendidikan kesehatan terhadap kemampuan remaja puteri dalam perawatan organ reproduksi. Holistik jurnal kesehatan, 13(1), 7683.

Suryati, B. (2012). Perilaku kebersihan remaja saat menstruasi. Jurnal Health Quality, 3(1), 54-65.

Thakre, S. B., Thakre, S. S., Reddy, M., Rathi, N., Pathak, K., \& Ughade, S. (2011). Menstrual hygiene: knowledge and practice among adolescent school girls of Saoner, Nagpur district. J Clin Diagn Res, 5(5), 1027-33.

Yusiana, M. A., \& Saputri, M. S. T. (2016). Perilaku menstrual hygiene remaja puteri pada saat menstruasi. Jurnal STIKES RS Baptis Kediri, 9(1).

Lia Lajuna', Nurlaili Ramli ${ }^{2}$, Nora Liana ${ }^{3}$ Jurusan Kebidanan, Politeknik Kesehatan Kemenkes Aceh. Email: lialajuna988@gmail.com 